\title{
Hypertension in the 1980s
}

WILLIAM A. NICKEY, D.O.

Philadelphia, Pennsylvania

\author{
Factors considered in this \\ review of hypertension include the \\ epidemiology and prevalence of the \\ disease, diagnostic criteria for its \\ definition, review of several major trials \\ and their significance, and \\ recommended guidelines for \\ nonpharmacologic and pharmacologic \\ intervention and treatment.
}

The development, in the United States, of a systematic body of knowledge of hypertension and its consequences originated in 1925 with the Society of Actuaries analyses of the insured population. In 1962, the Health Examination Survey issued the first prevalence estimates on hypertensive disease. Studies and reports of the 1980 s, from multicenter groups such as the Third Joint National Committee on Detection, Evaluation and Treatment of High Blood Pressure (JNC III), ${ }^{1}$ the European Working Party on High Blood Pressure in the Elderly, ${ }^{2}$ and the Systolic Hypertension in the Elderly Program (SHEP), ${ }^{3}$ unlike earlier studies, include institutionalized, military, elderly, and young populations.

By 1984, the U.S. hypertensive population, including both adults and children, was estimated to be greater than 60 million. ${ }^{1}$

The incidence of hypertension is greatly increased in elderly and black populations. Elderly hypertensives reportedly constitute the fastest growing segment of the high blood pressure population. ${ }^{3}$ The adult black population has demonstrated an incidence of hypertension of almost 40 percent, ${ }^{4}$ with the incidence in the elderly almost twice as high.

The magnitude of these estimates ranks hypertension as the most common chronic, life-threatening disease in our country compared to epidemiologic estimates of other diseases, and, certainly, as the single most important risk factor for the development of cardiovascular disease. Hypertension also figures as a major causative factor in stroke, coronary heart disease, hypertensive heart disease, and in more than 1 million heart attacks yearly. In addition to the human cost in morbidity and mortality, the total economic cost has been estimated at $\$ 8$ billion annually ${ }^{5}$

\section{Definitions}

Prior to 1980 , the estimated prevalence of hypertension was based on a blood pressure reading of 160/95 $\mathrm{mm}$. Hg or higher. The 1984 JNC III report ${ }^{1}$ revised the classifications downward. Table 1 lists the classification criteria and Tables 2 and 3 present followup criteria. Approximately 70 percent of the individuals who have been diagnosed as having high blood pressure are within the mild hypertension range. And mild hypertension causes "over 50 percent of the excess mortality attributable to hypertension." 6

\section{Changes in the last decade}

Since its inception in the early 1970 s, the National High Blood Pressure Education Program has made a positive impact by increasing professional and public awareness of the magnitude of hypertension as a disease and the consequences of sustained elevated blood pressure. This knowledge has increased the number and frequency of visits to physicians for diagnosis and treatment of hypertension by 55 percent. ${ }^{7}$ In comparison, the increase in physician office visits for other causes is far less.

\section{Results of therapy trials}

Whether to treat mild hypertension has been a subject of considerable debate. The effect of active treatment of mild to moderate hypertension in five large trials is presented in Table $4 .^{6}$ The mortality for severe accelerated and malignant hypertension is so high that controlled trials aimed at assessing benefit often were not considered necessary.

\section{Veterans Administration Study Group}

Two VA trials were conducted and results were published in 1969 and 1970. The first trial evaluated males with a diastolic blood pressure of $115-129 \mathrm{~mm}$. Hg. There was a greater than 90 percent reduction in fatal or serious morbid events per year in the treated group. ${ }^{8}$ A reduction in diastolic blood pressure occurred in 59 percent of the treated mild to moderate group, and progression of the disease was arrested. In $15-20$ percent of the untreated group with mild to moderate hypertension, the disease progressed to a more severe level. The sec- 


\begin{tabular}{|c|c|}
\hline Blood pressure range (mm. $\mathrm{Hg})$ & Classification* \\
\hline \multicolumn{2}{|c|}{ Diastolic } \\
\hline$<85$ & Normal \\
\hline $85-89$ & High normal \\
\hline $90-104$ & Mild hypertension \\
\hline $105-114$ & Moderate hypertension \\
\hline$\geqslant 115$ & Severe hypertension \\
\hline \multicolumn{2}{|c|}{$\begin{array}{l}\text { Systolic (when diastolic pressure } \\
\text { is }<90 \mathrm{~mm} . \mathrm{Hg} \text { ) }\end{array}$} \\
\hline$<140$ & Normal \\
\hline $140-159$ & $\begin{array}{l}\text { Borderline isolated systolic } \\
\text { hypertension }\end{array}$ \\
\hline$\geqslant 160$ & Isolated systolic hypertension \\
\hline \multicolumn{2}{|c|}{$\begin{array}{l}\text { *A classification of borderline isolated or isolated systolic hypertension } \\
\text { takes precedence over one of high normal blood pressure. A classification } \\
\text { of high normal diastolic pressure takes precedence over one of normal } \\
\text { systolic pressure. }\end{array}$} \\
\hline
\end{tabular}

TABLE 2. 1984 JNC III FIRST-OCCASION MEASUREMENT FOLLOW-UP CRITERIA FOR PERSONS 18 YEARS OF AGE OR OLDER. ${ }^{1}$

Blood pressure range (mm. Hg) Recommendations*

\begin{tabular}{|c|c|}
\hline \multicolumn{2}{|l|}{ Diastolic } \\
\hline$<85$ & Recheck pressure within 2 years \\
\hline $85-89$ & Recheck pressure within 1 year \\
\hline $90-104$ & $\begin{array}{l}\text { Confirm promptly (within } 2 \\
\text { months) }\end{array}$ \\
\hline $105-114$ & $\begin{array}{l}\text { Evaluate or refer promptly } \\
\text { (within } 2 \text { weeks) }\end{array}$ \\
\hline$\geqslant 115$ & Evaluate or refer immediately \\
\hline \multicolumn{2}{|c|}{$\begin{array}{l}\text { Systolic (when diastolic } \\
\text { pressure is }<90 \mathrm{~mm} \text {. } \mathrm{Hg} \text { ) }\end{array}$} \\
\hline$<140$ & Recheck pressure within 2 years \\
\hline $140-199$ & $\begin{array}{l}\text { Confirm promptly (within } 2 \\
\text { months) }\end{array}$ \\
\hline$\geqslant 200$ & $\begin{array}{l}\text { Evaluate or refer promptly } \\
\text { (within } 2 \text { weeks) }\end{array}$ \\
\hline
\end{tabular}

*When follow-up recommendations differ for diastolic and systolic blood pressures, the shorter recommended time period takes preference, and a referral supersedes a recommendation for rechecking.

ond trial evaluated the relationship between placebo and active treatment in a group of men with diastolic blood pressure of $90-114 \mathrm{~mm}$. Hg. There was a 78 percent reduction in events, although this was seen only in the group with a diastolic blood pressure in the $105-114 \mathrm{~mm}$. $\mathrm{Hg}$ range. ${ }^{9}$ The trials demonstrated that reducing blood pressure in patients with a diastolic pressure above $105 \mathrm{~mm}$. Hg reduced mortality. Therefore, at that time no data from clinical trials supported a benefit in treating mild hypertensives at the lower range of blood pressure elevation.

United States Public Health Service Study. In its findings reported in 1979, this 7- to 10 -year trial demonstrated a reduction in disease progression in patients actively treated for diastolic blood pressure in the $90-114 \mathrm{~mm}$. Hg range. ${ }^{10,11}$ The incidence of cerebrovascular events decreased and left ventricular hypertrophy was reversed in the treated group.

\section{The Australian Therapeutic Trial in Mild Hypertension}

In this study, ${ }^{12} 3,427$ patients with diastolic blood pressures between 95 and $109 \mathrm{~mm}$. Hg randomly received either an antihypertensive agent or placebo for an average 4 years. The results showed a significant reduction in mortality for the treated group. Cardiovascular disease-related deaths were reduced by 66 percent, but for every 1,000 person years of treatment, only 1.5 lives were saved. Cerebrovascular events, both fatal and nonfatal, were reduced by 50 percent. Only 25 percent of the controls achieved average diastolic blood pressures of $90 \mathrm{~mm} . \mathrm{Hg}$ or below, compared with 65 percent of the treated subjects.

\section{The Oslo Study}

Over a period of 5 years, 785 patients with hypertension in the $90-110 \mathrm{~mm}$. $\mathrm{Hg}$ range were treated with an active drug or given a placebo. ${ }^{13}$ Although therapy decreased deaths from cerebrovascular accidents, the decrease in mortality from myocardial infarction was insignificant. The results overall were inconclusive for validating the effect of antihypertensive treatment on mortality or prevention of coronary heart disease. However, treatment had a significant preventative effect on incidence of stroke, dissecting aneurysm, coronary heart failure, and marked left ventricular hypertrophy.

\section{The Hypertension Detection and Follow-up Program (HDFP)}

This 5-year, community-based, surveillance trial recruited 10,940 hypertensive patients between 30 and 69 years of age screened from a population of 158,000 . Unlike trials that compared placebos with active therapy, HDFP researchers ${ }^{14}$ studied a population of patients with diastolic blood pressures of 90-114 mm. Hg, all of whom received antihypertensive treatment. The subjects were randomly divided into two treatment groups: (1) the referredcare (RC) group received the customary care available in their communities, irrespective of supervision or follow up; and (2) the stepped-care (SC) group received the treatment advocated by the First Joint National Committee on Detection, Evaluation and Treatment of High Blood Pressure in special hypertension centers. Within each treatment group, over 70 percent of the patients fit the classification criteria for mild hypertension.

Notably, about 65 percent of SC and 44 percent of RC patients in all categories (mild, moderate, severe) achieved goal diastolic blood pressure or less. For mild hypertensives, 64 percent of the SC group versus 43 percent of the $\mathrm{RC}$ group achieved goal diastolic blood pressure $(\leqslant 90 \mathrm{~mm}$. $\mathrm{Hg})$. 
For all patients in the trial, mortality was reduced by 16.9 in SC patients versus RC patients. In the mild hypertension category, the SC group had 20 percent fewer deaths from all causes than the RC group. The moderate and severe hypertension categories showed smaller differences (13 percent and 7 percent, respectively) in mortality reduction, but again the results favored the SC group. Conventionally, patients with higher elevations in blood pressure were treated more aggressively, which may explain the less significant decreases in mortality exhibited in the moderate and severe groups. The mortality rate for all causes in patients below 50 years of age in the mild hypertensive category was not significantly different between the SC and RC groups. A notable finding in the study results, which supports the case for early

TABLE 3. 1984 JNC III SECOND-OCCASION MEASUREMENT FOLLOW-UP CRITERIA FOR PERSONS 18 YEARS OF AGE OR OLDER. ${ }^{1}$

\begin{tabular}{|ll|}
\hline Blood pressure range $(\mathrm{mm} . \mathrm{Hg})$ & \multicolumn{1}{c}{ Recommendations* } \\
\hline Diastolic & Recheck within 2 years $\dagger$ \\
$<85$ & Recheck within 1 year \\
$85-89$ & Evaluate or refer promptly \\
290 &
\end{tabular}

Systolic (when diastolic pressure is $<90 \mathrm{~mm}$. Hg) $\begin{array}{ll}<140 & \text { Recheck within 1 year } \\ \geqslant 140 & \text { Evaluate or refer promptl }\end{array}$

*When follow-up recommendations differ for diastolic and systolic blood pressures, the shorter recommended time period takes precedence and a referral supersedes a recommendation.

†Rechecking within 1 year is recommended for persons who are at increased risk of progressing to higher blood pressures. This category includes persons who meet one or more of the following criteria: history of hypertension or cardiovascular event, weight gain or obesity, black race, use of an oral contraceptive, and excessive ethanol consumption. treatment, was the marked increase in mortality in both groups for patients with preexisting organ damage.

For mild hypertensives in the SC group, as compared to the $\mathrm{RC}$ group, there were 45 percent and 20 percent fewer deaths from cerebrovascular diseases and coronary heart disease, respectively. In a subgroup analysis of mild hypertensives, mortality decreased by 21.9 percent in SC patients with pretreatment diastolic blood pressure in the 90-94 $\mathrm{mm} . \mathrm{Hg}$ range compared to $\mathrm{RC}$ patients. Similarly, in the $95-99 \mathrm{~mm} . \mathrm{Hg}$ range there was a 23.1 percent decrease favoring the $\mathrm{SC}$ group. ${ }^{15}$ The incidences of stroke, angina, and myocardial infarction also were lower in the $\mathrm{SC}$ group than in the $\mathrm{RC}$ group.

Therapeutic intervention: Conclusions from the HDFP study. Considering (1) the overall reduction in mortality and morbidity and the global reduction in blood pressure in the three strata of patients studied, (2) the greater reduction in morbidity and mortality for stepped-care versus referred-care, and (3) that mild hypertensives comprise 70 percent of the estimated 60 million persons with the disease, the results of the HDFP study reinforce the potential benefits of treating mild hypertension.

\section{Medical Research Council (MRC) Working Party}

The MRC, a single-blind, placebo-controlled trial also looked at the benefit of treatment in mild hypertension. ${ }^{14}$ The population recruited numbered 17,354 patients observed for a total of 85,572 pa-

TABLE 4. PREVENTION OF PROGRESSION FROM MILD TO MORE SEVERE HYPERTENSION. FINDINGS FROM MAJOR THERAPEUTIC CLINICAL TRIALS (ADAPTED FROM MOSER, BLACK, AND STAIR ${ }^{6}$ ).

\begin{tabular}{|c|c|c|c|c|c|}
\hline Study & $\begin{array}{l}\text { Range for } \\
\text { mild } \\
\text { hypertension } \\
(\mathrm{mm} . \mathrm{Hg})\end{array}$ & $\begin{array}{l}\text { Total } \\
\text { number }\end{array}$ & $\begin{array}{l}\text { Number } \\
\text { who } \\
\text { progressed }\end{array}$ & $\begin{array}{l}\text { Total } \\
\text { number }\end{array}$ & $\begin{array}{l}\text { tment } \\
\text { ts } \\
\text { Number } \\
\text { who } \\
\text { progressed }\end{array}$ \\
\hline $\begin{array}{l}\text { USPHS Hospitals } \\
\text { Intervention } \\
\text { Trial (1979) }\end{array}$ & $90-114$ & 196 & $24 *$ & 193 & 0 \\
\hline $\begin{array}{l}\text { Veterans Administration } \\
\text { Cooperative Study } \\
\text { Group (1970) }\end{array}$ & $90-114$ & 194 & 20 & 186 & 0 \\
\hline $\begin{array}{l}\text { Australian Therapeutic } \\
\text { Trial }(1980) \\
\text { Oslo Study }(1980) \dagger\end{array}$ & $\begin{array}{l}95-109 \\
90-110\end{array}$ & $\begin{array}{r}1,706 \\
379\end{array}$ & $\begin{array}{r}202 \\
65\end{array}$ & $\begin{array}{r}1,721 \\
406\end{array}$ & $\begin{array}{l}5 \\
1\end{array}$ \\
\hline $\begin{array}{l}\text { Medical Research } \\
\text { Council Working } \\
\text { Party (1985) } \\
\text { Totals }\end{array}$ & $90-109$ & $\frac{8,654}{11,129}$ & $\frac{1,011}{1,322}$ & $\frac{8,700}{11,206}$ & $\frac{76}{82}$ \\
\hline
\end{tabular}


tient years. Patients were randomly assigned to treatment with bendrofluazide $(n=4,297)$, or propranolol $(n=4,403)$, or to placebo $(n=8,654)$. The primary aim of this group was to determine whether drug treatment of diastolic hypertension in the $90-109 \mathrm{~mm}$. Hg range in men and women aged 35 to 64 years would reduce rates of stroke, coronary events, and death due to hypertension. A secondary aim was to compare the course of blood pressure in three groups of patients.

The primary results of comparison between the treatment and placebo categories were reductions in stroke rate (60 strokes in the two treated groups versus 109 in the placebo group) and cardiovascular events (286 and 352 events in the treated and placebo groups, respectively). Comparison of results for the two drugs indicated that propranolol reduced stroke and coronary event rate, but only in nonsmokers. Bendrofluazide was significantly more effective than propranolol in reducing stroke rate both in nonsmokers and smokers and achieved better blood pressure control than propranolol; however, it did not reduce the coronary event rate in smokers or nonsmokers.

A large number $(1,011)$ of the placebo subjects in the MRC trial progressed to more severe hypertensive disease in the course of the study, whereas only 76 of the 8,700 patients in the active treatment contingent progressed to more severe blood pressure elevation. Overall, depending upon the agent used in therapy, 33-50 percent of patients in the two treatment groups showed a reduction in blood pressure to normotensive, whereas only 18 percent in the placebo group did.

\section{Report from the Joint National Committee}

The 1984 JNC III report ${ }^{1}$ has influenced the treatment of high blood pressure through revision of the definitions for diagnosis of mild hypertension, identification and definition of systolic hypertension, identification of special hypertensive populations at risk, recommendation of nonpharmacologic strategies for treating borderline hypertension, and liberalization of stepped-care treatment guidelines. JNC III also identified patient groups that present special management problemsblacks, patients with coronary artery disease, renal impairment, and/or diabetes mellitus, and those with preeclampsia or the hypertension of pregnancy.

\section{New treatment guidelines}

Nonpharmacologic intervention

The report of $\mathrm{JNC}^{\mathrm{III}}{ }^{1}$ recommended nonpharmacologic therapies for patients who present with initially borderline/mild hypertension $(>140 / 90$ $\mathrm{mm} . \mathrm{Hg}$ ) until subsequent periodic evaluation establishes a constant elevation. Nonpharmacologic therapy consists of lifestyle changes, including reduction of weight, reduction of sodium, alcohol, and saturated fat intake, cessation of smoking, addition of moderate exercise, and behavior modification. The importance of nonpharmacologic treatment should be stressed, even if medication becomes necessary, no matter what the level of blood pressure elevation. This is not to be considered an "either-or" measure for blood pressure control. It has been found that only a small percentage of patients who have mild hypertension clinically respond to these strategies with a return to normotensive blood pressures. For nonresponders, specific pharmacologic therapy is necessary.

\section{Pharmacologic therapies}

Table 4 compared trial results from active treatment versus placebo groups and establishes the benefits of pharmacologic intervention in patients with mild to moderate hypertension. The primary goal of such intervention is to reduce diastolic blood pressure below $90 \mathrm{~mm}$. $\mathrm{Hg}$, or, as an alternative, to the lowest point consistent with patient drug tolerance and safety. Because the success of treatment depends in part on a patient's lifetime commitment to therapeutic compliance and, indirectly, to his/ her tolerance of drug side effects, this aspect is at last receiving the attention it warrants. Data from a subgroup analysis ${ }^{17}$ of 5,485 patients in the HDFP trial demonstrate that nearly a third of treated patients discontinued drug therapy because of putative side effects.

Since JNC III liberalized treatment guidelines and recognized the appropriateness of either a diuretic or beta-blocker for initial therapy, newer agents that are essentially free of the symptomatic and metabolic side effects associated with traditional therapies have become available. In 1985, the Food and Drug Administration approved the use of angiotensin-converting enzyme (ACE) inhibitors as initial therapy in all degrees of hypertension. Subsequently, a multicenter study by Croog and Associates $^{18}$ of 626 men with mild-to-moderate hypertension found that patients taking the ACE inhibitor captopril scored significantly higher on measures of general well being and had fewer side effects than patients taking propranolol or methyldopa, the other antihypertensive therapies evaluated.

This study is the first comprehensive effort to determine the effect of antihypertensive treatment on quality of life. What are its implications for clinicians? In an accompanying editorial, Chobanian ${ }^{19}$ advises, "The goal of therapy should be not 
only to reduce morbidity and mortality but to do so without adverse effects on the functional wellbeing of our patients." In this way, we redouble the benefits of therapy by enhancing the prospects for compliance.

\section{Conclusions}

Control of hypertension begins with detection via wide-scale screening of a population made aware of the dangers of hypertension through public education programs. It also requires continued observation and treatment. The results of several studies in which pharmacologic treatment was initiated in the early, mild stages of hypertension (diastolic blood pressure 90-104 mm. Hg) have been impressive. Progression to more severe hypertensive disease was virtually arrested in treated patients, whereas 10 to 25 percent of untreated mild hypertensives progressed to more severe hypertension (diastolic blood pressure $>110 \mathrm{~mm}$. $\mathrm{Hg}$ ). The numbers of strokes and coronary events were decreased significantly in treated versus placebo groups of mild to moderate hypertensives. In many cases, left ventricular hypertrophy was prevented or reversed.

These overall findings support aggressive treatment of high blood pressure, including pharmacologic intervention for mild hypertension. Unfortunately, most trials report dropout rates up to 33 percent because of adverse effects from traditional therapy. However, the new ACE inhibitor captopril has been shown to provide safe and effective treatment while preserving or improving the patient's quality of life.

1. Joint National Committee on Detection, Evaluation and Treatment of High Blood Pressure: 1984 Report. JAOA 83:642-59, May 84

2. European Working Party on High Blood Pressure in the Elderly:
Mortality and morbidity results from the European Working Party on High Blood Pressure in the Elderly Trial. Lancet 1:1349-54, 15 Jun 85 3. Hulley, S.B., et al.: Systolic Hypertension in the Elderly Program (SHEP). Antihypertensive efficacy of chlorthalidone. Am J Cardiol 56:913-20, 1 Dec 85

4. American Heart Association: 1986 Heart facts. AHA Publications, Dallas, Texas, 1986

5. Levy, R.I.: Eighth report of the Director, NHLBI, U.S. Dept. of HHS, PHS, NIH Publication 82-2103, Mar 81

6. Moser, M., Black, H., and Stair, D.: The dilemma of mild hypertension. Drugs 31:279-87, 1986

7. Lenfant, Rocella, E.J.: Trends in hypertension control in the United States. Chest 86:459-62, Sep 84

8. Veterans Administration Cooperative Study Group on Antihypertensive Agents: Effects of treatment on morbidity in hypertension. Results in patients with diastolic blood pressures averaging 115 through $129 \mathrm{~mm} \mathrm{Hg}$. JAMA 202:1028-34, 11 Dec 67

9. Veterans Administration Cooperative Study Group on Antihypertensive Agents: Effects of treatment on morbidity in hypertension. Results in patients with diastolic blood pressures averaging 90 through $114 \mathrm{~mm} \mathrm{Hg}$. JAMA 213:1143-52, 17 Aug 70

10. Moser, M.: The case for treating mild hypertension. J Cardiovasc Pharmacol 7:S102-8, 1985

11. Smith, W.M., Edlavitch, S.C., and Krushat, W.M.: U.S. Public Health Service hospitals intervention trial in mild hypertension. In Hypertension-determinants, complications, and intervention, edited by G. Onesti and C.B. Climt. Grune and Stratton, New York, 1979, pp. 381-99

12. Reader, R., et al.: The Australian therapeutic trial in mild hypertension. Lancet 1:1261-7, 14 Jun 80

13. Helgeland, A.: Treatment of mild hypertension. A five year controlled drug trial. The Oslo study. Am J Med 69:725-32, Nov 80

14. Hypertension Detection and Follow-up Program Cooperative Group: Five-year findings. 1. Reduction in mortality of persons with high blood pressure, including mild hypertension. JAMA 242:2562-71, 7 Dec 79

15. Schoenberger, J.A.: Mild hypertension. The rationale for treatment. Am Heart J 112:872-6, Oct 86

16. Medical Research Council Working Party: MRC trial of treatment of mild hypertension. Principal results. Br Med J 291:97-104, 13 Jul 85

17. Curb, J.D., et al.: Long-term surveillance for adverse effect of antihypertensive drugs. JAMA 253:3263-8, 14 Jun 85

18. Croog, S.H., et al.: The effects of antihypertensive therapy on the quality of life. N Engl J Med 314:1657-64, 26 Jun 86

19. Chobanian, A.V.: Antihypertensive therapy in evolution (editorial). N Engl J Med 314:1701-2, 26 Jun 86

Dr. Nickey is professor and chairman, Department of Internal Medicine, and head, Division of Nephrology and Hypertension, Osteopathic Medical Center of Philadelphia, Philadelphia.

Dr. Nickey, Osteopathic Medical Center of Philadelphia, 4150 City Avenue, Philadelphia, Pennsylvania 19131. 